\title{
The Effect of Antepartum Depression on the Outcomes of Pregnancy and Development of Postpartum Depression A prospective cohort study of Omani women
}

Aisha Al Rawahi, ${ }_{1}^{\text {*}}$ Maisa H. Al Kiyumi, ${ }^{2}$ Raya Al Kimyani, ${ }^{3}$ Iman Al-Lawati, ${ }^{1}$ Sathiya Murthi, ${ }_{4}^{4}$ Robin Davidson, ${ }^{5}$ Abdullah Al Maniri, ${ }^{6}$ Mohammed Al Azri ${ }^{2}$

$$
\begin{aligned}
& \text { تأثير إكتئاب ما قبل الولادة على نتائج الحمل وحدوث إكتئاب ما بعد الولادة } \\
& \text { دراسة استقصائية أترابية للنساء العمانيات }
\end{aligned}
$$

عائشة الرواحية، مايسة حمد الكيومية، ريا الكميانية، إيمان اللواتية، ساثيا مورثي، روبن ديفيدسون، عبد الله المنيري، محمد العزري

ABSTRACT: Objectives: This study aimed to identify the relationship between antenatal depression and pregnancy outcomes, including the risk of developing postpartum depression in Oman. Methods: This follow-up prospective longitudinal cohort study included pregnant women attending primary healthcare institutions in Muscat, Oman from January to November 2014. The Edinburgh Postnatal Depression Scale (EPDS) was used to screen for antenatal and postnatal depression. Pregnant Omani women with a gestational age $\geq 32$ weeks attending 12 local health centres for antenatal care in Muscat were invited to participate. Recruited women were followed-up at 6-8 weeks after delivery. The following pregnancy outcomes were assessed: mode of delivery (normal or Caesarean section [CS]), gestational age at delivery (preterm or fullterm), baby's birth weight and development of postnatal depression. Results: A total of 959 women participated in this study (response rate: 97.3\%). In total, 233 women (24.4\%) had antenatal depression with a score of $\geq 13$ on the EPDS. Of the 592 participants $(61.7 \%)$ who attended postnatal clinics at 6-8 weeks post-delivery, 126 (21.3\%) were positive for postnatal depression. Logistic multivariate regression analysis showed that antenatal depression was associated with increased risk of CS (odds ratio $[\mathrm{OR}]=1.79 ; 95 \%$ confidence interval $[\mathrm{CI}]: 1.20-2.66)$ and postnatal depression $(\mathrm{OR}=8.63$; $95 \% \mathrm{CI}$ : 5.56-13.39). Conclusion: Screening women for antenatal depression and providing appropriate management may reduce adverse pregnancy outcomes and the risk of developing postnatal depression.

Keywords: Depression; Postnatal depression; Women Health Services; Maternal Health Services; Pregnancy; Primary Health Care; Oman.

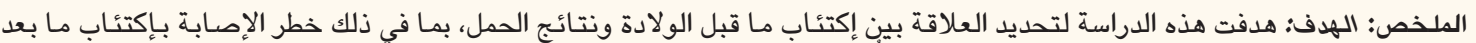

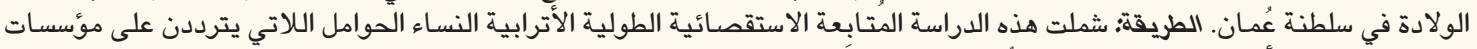

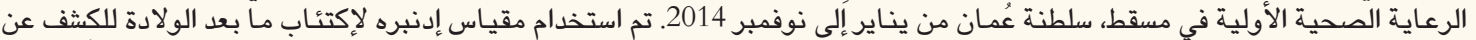

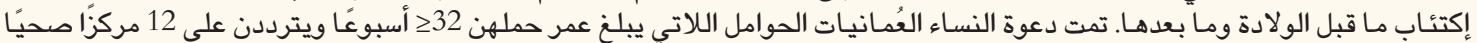

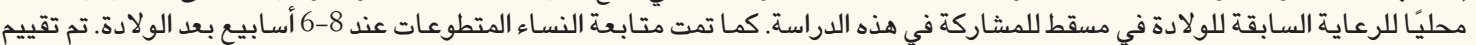

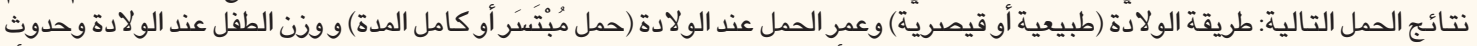

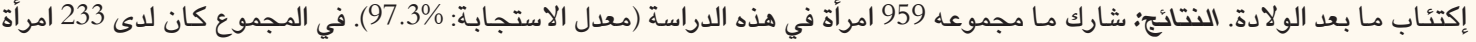

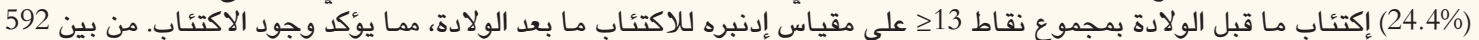

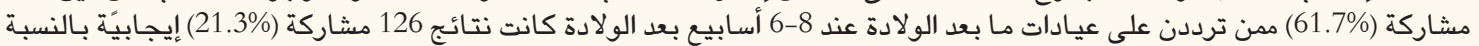

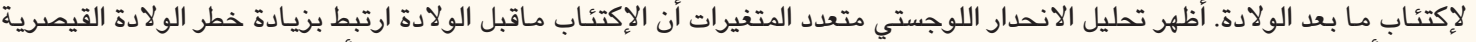

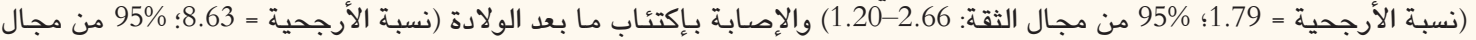
الثقة: 13.39-5.56). الخلاصة: فحص الإدة النساء للكشف عن إكتئاب مـا قبل الولادة وتوفير العلاج الملائم قد يقلل من نتائج الحمل السلبية وخطر

$$
\text { الإصـابة بـاكتئاب ما بعد الولادة. }
$$

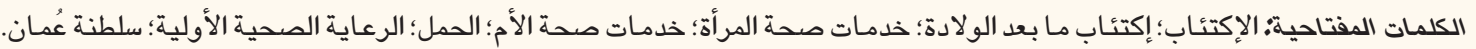

\footnotetext{
Advances in KNOWLEDGE

This cohort study was the first conducted in Oman to examine the relationship between antenatal depression and pregnancy outcomes, including the development of postnatal depression.

Understanding the relationship between antepartum and postpartum depression should help identify women who are at greater risk of developing postpartum depression, resulting in early detection and treatment.

Identifying the effects of antenatal depression on the outcomes of pregnancy, such as birth weight and mode of delivery, should help health practitioners understand the relationship of such associations.
}

Departments of ${ }^{1}$ Family Medicine \& ${ }^{3}$ Woman and Child Health, Directorate General of Primary Health Care, Ministry of Health, Muscat, Oman; ${ }^{2}$ Department of Family Medicine \& Public Health, Sultan Qaboos University Hospital, Muscat, Oman; ${ }^{4}$ Research Section $\mathcal{E}^{6}$ Department of Strategy and Planning, Oman Medical Specialty Board, Muscat, Oman; ${ }_{5}^{5}$ Severnside Integrated Urgent Care Service, Bristol, UK.

"Corresponding Author's e-mail: Drmaysa@squ.edu.om 


\section{Application to Patient Care}

A screening programme for pregnant women should be considered at the primary care level. Women found to be depressed during pregnancy might be offered treatment, including referrals to psychology or psychiatry outpatient clinics depending on the severity of depression, resulting in the attenuation of the detrimental effects of depression by early detection and treatment.

Women with antepartum depression should be followed-up during the postnatal period and rescreened as screening all women during the postpartum period might not always be feasible.

Women with adverse pregnancy outcomes might have had antenatal depression. Thus, targeting women by screening for antenatal depression and treating or referring them for further care may help reduce pregnancy-related complications and improve maternal and infant well-being.

A

NTENATAL DEPRESSION IS CONSIDERED A major cause of disability among women worldwide, particularly in low-income countries; both antenatal and postnatal depression are associated with detrimental effects on child development. ${ }^{1,2}$ Several risk factors for antenatal depression have been reported, including low socioeconomic status and educational level, a lack or unavailability of social support, experiencing physical violence from a spouse, poor partner relationships, alcohol abuse and a history of psychiatric morbidities such as depression, anxiety and stress. ${ }^{3-5}$ A recent study conducted in Oman revealed that unplanned pregnancy and marital conflicts were significant predictors of antenatal depression. ${ }^{6}$

Antenatal depression is frequently undetected by doctors and therefore left untreated, which may lead to adverse effects on both mother and baby. ${ }^{7}$ For the mother, antenatal depression increases the risk of preeclampsia, Caesarean section (CS), assisted vaginal delivery, epidural analgaesia use during delivery, suicidal ideation and the development of postnatal depression. ${ }^{8,9}$ For the baby, antenatal depression has been found to increase the risk of spontaneous preterm delivery, low birth weight (LBW), intensive neonatal care admission and sudden death. ${ }^{8}$ In addition, babies of women with antenatal depression are more at risk of receiving suboptimal care from their mothers after birth and during their growth. ${ }^{10}$

Antenatal depression has been reported as the strongest predictor of postnatal depression. ${ }^{3}$ Several consequences are associated with postnatal depression including marital conflict, self-harm, suicidal thoughts and the development of depressive symptoms in fathers. ${ }^{11}$ Indeed, it has been found that children of mothers who had postnatal depression were more likely to have impairment of cognitive and emotional functioning, receive less psychological care and suffer neglect and experience a disturbance in the ability to breastfeed. ${ }^{12}$ Thus, it has been suggested that early detection and treatment of maternal depression could have a positive impact on preventing offspring depression, especially during adulthood. ${ }^{13}$

Currently, in Oman the risk for depression is not included as part of routine antenatal or postnatal screening or assessments. Oman is an Arabian Gulf country with an estimated population of 4.6 million, of which 2.5 million are Omani and 2.1 million are expatriates. ${ }^{14}$ Almost one-third of Omanis (35\%) are below 15 years old, and only $3.5 \%$ of the population are above 65 years old. ${ }^{14}$ In Oman, primary health centres are the portal to accessing secondary and tertiary healthcare services. Primary healthcare facilities are funded by the government and all Omanis and nonOmanis who are sponsored by the government have access to these services at all levels. Private institutions providing healthcare services are also present.

Standard antenatal care services are provided in local health centres (LHCs) as soon as a woman becomes pregnant. Each pregnant woman is issued an antenatal 'green card' that includes personal details, medical history, family history, details of previous pregnancies and the results of routine antenatal investigations. The card also includes information about the current pregnancy, including type and time of delivery and baby's birth weight and Apgar score.

Women with low-risk pregnancies make six antenatal visits to LHCs during their pregnancy. Pregnancies rated as high-risk are referred through specific protocols to secondary or tertiary hospitals and receive care appropriate to their condition. Women usually deliver in local secondary or tertiary hospitals and are followed-up in their LHCs at 6-8 weeks for postnatal care..$^{15}$ During their postnatal visit, women are examined and investigated medically as required and counselled regarding birth spacing. Antenatal and postnatal clinics are mainly staffed by female general practitioners with the help of a specialised nurse.

To the best of the authors' knowledge, no previously published cohort-based studies on antenatal and postnatal depression have been undertaken in Oman. Therefore, this study aimed to identify the relationship between antenatal depression and pregnancy outcomes, including the development of postnatal depression, in Oman.

\section{Methods}

This prospective longitudinal cohort study included pregnant women attending primary healthcare institutions from January to November 2014 in Muscat, 
Oman. This study is an extension of a previous study that assessed the prevalence and risks of antenatal depression among Omani women attending primary healthcare centres. ${ }^{6}$ Women who had medical conditions such as gestational diabetes (GDM), hypertension, pregnancy-induced hypertension or who were receiving treatment for depression were excluded as were nonOmani women. ${ }^{6}$

In total, 12 out of 32 LHCs in Muscat were randomly selected to conduct the current study. Three nurses from each LHC were trained on how to administer the questionnaire to women and to collect data on pregnancy outcomes. All pregnant Omani women at a gestational age of $\geq 32$ weeks who attended their LHCs for routine antenatal care visits were identified and invited by nurses to participate in the study. ${ }^{6}$

Sample size was calculated based on a presumed prevalence rate of 20\%, 95\% confidence interval (CI) and an error rate of $2 \%$. The required sample size was 1,000 .

The Arabic version of the self-administered Edinburgh Postnatal Depression Scale (EPDS) was used as a screening tool to identify both antenatal and postnatal depression in the current study. This validated, reliable questionnaire comprises 10 questions where each question is scored from $0-3$ for a total score ranging from $0-30$. A score of $\geq 13$ is indicative of probable antenatal or postnatal depression. ${ }^{3,16}$ The Arabic version of the EPDS was validated and used in a study conducted in an Arabic-speaking country. ${ }^{3}$ Permission to use the Arabic version of the EPDS was obtained from the corresponding author. This questionnaire was administered twice, once during the antenatal visit and again during a postnatal follow-up appointment.

Social, demographic and medical characteristics of women were recorded in a separate section and were attached to the EPDS questionnaire. These characteristics include age, education level, occupation, gestational age, gravidity and whether the pregnancy was planned or not.

The recruited women were followed-up postnatally at 6-8 weeks and were given the EPDS questionnaire to complete for a second time. Women who did not attend the postnatal visit were reminded to do so via telephone. ${ }^{6}$ The pregnancy outcomes were collected 6-8 weeks after delivery during the routine postnatal visit, with data collected from the green card' and the birth register available in the LHCs. The collected data included type of delivery (i.e. normal vaginal delivery or CS), gestational age at time of delivery and baby's birth weight.

Preterm birth was defined as delivery at $<37$ weeks of gestation. Birth weight of less than $2.5 \mathrm{~kg}$ was
Table 1: Baseline sociodemographic and antenatal and postnatal characteristics of pregnant Omani women $(\mathrm{N}=959)$

\begin{tabular}{|c|c|}
\hline Characteristic ${ }^{*}$ & n (\%) \\
\hline \multicolumn{2}{|l|}{ Age in years $(\mathrm{n}=957)$} \\
\hline$<24$ & $261(27.3)$ \\
\hline $25-30$ & $451(47.1)$ \\
\hline$>30$ & $245(25.6)$ \\
\hline \multicolumn{2}{|l|}{ Occupation $(\mathrm{n}=959)$} \\
\hline Housewife & $609(63.5)$ \\
\hline Employed & $350(36.5)$ \\
\hline \multicolumn{2}{|l|}{ Highest level of education $(n=957)$} \\
\hline Basic education & $519(54.2)$ \\
\hline University \& higher education & $438(45.8)$ \\
\hline \multicolumn{2}{|l|}{ Planned pregnancy $(\mathrm{n}=958)$} \\
\hline Yes & $560(58.5)$ \\
\hline No & $398(41.5)$ \\
\hline \multicolumn{2}{|l|}{ Gravidity $(\mathrm{n}=959)$} \\
\hline Primigravida (1 pregnancy) & $373(38.9)$ \\
\hline Multigravida ( $2-4$ pregnancies) & $465(48.5)$ \\
\hline Grand multigravida (5+ pregnancies) & $121(12.6)$ \\
\hline \multicolumn{2}{|l|}{ Gestational age in weeks $(\mathrm{n}=959)$} \\
\hline $32-34$ & $399(41.6)$ \\
\hline $35-37$ & $376(39.2)$ \\
\hline$>37$ & $184(19.2)$ \\
\hline \multicolumn{2}{|l|}{ History of miscarriage $(\mathrm{n}=959)$} \\
\hline Yes & $170(17.7)$ \\
\hline No & $789(82.3)$ \\
\hline \multicolumn{2}{|l|}{ Antenatal depression $(\mathrm{n}=959)$} \\
\hline Depressed & $233(24.3)$ \\
\hline Not depressed & $726(75.7)$ \\
\hline \multicolumn{2}{|c|}{ Gestational age at delivery in weeks $(n=953)$} \\
\hline$<37$ & $59(6.2)$ \\
\hline$\geq 37$ & 894 (93.8) \\
\hline \multicolumn{2}{|l|}{ Type of delivery $(\mathrm{n}=953)$} \\
\hline Normal vaginal delivery & $822(86.3)$ \\
\hline CS & $131(13.7)$ \\
\hline \multicolumn{2}{|l|}{ Type of CS $(n=131)$} \\
\hline Emergency & $108(82.4)$ \\
\hline Elective & $23(17.6)$ \\
\hline \multicolumn{2}{|l|}{ Birth weight of infant in $\mathrm{kg}(\mathrm{n}=952)$} \\
\hline$<2.5$ & $64(6.7)$ \\
\hline$\geq 2.5$ & $888(93.3)$ \\
\hline \multicolumn{2}{|l|}{ Postnatal depression $\dagger(\mathrm{n}=592)$} \\
\hline Depressed & $126(21.3)$ \\
\hline Not depressed & $466(78.7)$ \\
\hline \multicolumn{2}{|l|}{ CS = Caesarean section $; \mathrm{kg}=$ kilogram.} \\
\hline \multicolumn{2}{|c|}{$\begin{array}{l}\text { "As the current study is a continuation of a previous study, some data } \\
\text { are the same. } 6 \text { The total of each variable corresponds to the number } \\
\text { of respondents for each question. }{ }^{+} \text {A score of } \geq 13 \text { on the Edinburgh } \\
\text { Postnatal Depression Scale was indicative of probable antenatal or } \\
\text { postnatal depression. }\end{array}$} \\
\hline
\end{tabular}


Table 2: Associations between antenatal depression and outcomes of pregnancy and postnatal depression among pregnant Omani women $(\mathrm{N}=959)$

\begin{tabular}{|c|c|c|c|}
\hline \multirow[t]{3}{*}{ Variables } & \multicolumn{2}{|c|}{ n (\%) } & \multirow[t]{3}{*}{$P$ value } \\
\hline & \multicolumn{2}{|c|}{ Antenatal depression* } & \\
\hline & $\begin{array}{c}\text { Depressed } \\
(\mathbf{n}=233)\end{array}$ & $\begin{array}{c}\text { Not } \\
\text { depressed } \\
(\mathbf{n}=726)\end{array}$ & \\
\hline \multicolumn{3}{|c|}{ Birth weight of infant in $\mathrm{kg}$} & 0.177 \\
\hline$<2.5$ & $20(8.6)$ & $44(6.1)$ & \\
\hline$\geq 2.5$ & $213(91.4)$ & $682(93.9)$ & \\
\hline \multicolumn{3}{|c|}{ Gestational age at delivery in weeks } & 0.300 \\
\hline$<37$ & $11(4.7)$ & $48(6.6)$ & \\
\hline$\geq 37$ & $222(95.3)$ & $678(93.4)$ & \\
\hline \multicolumn{3}{|l|}{ Type of delivery } & $0.004+$ \\
\hline $\begin{array}{l}\text { Normal vaginal } \\
\text { delivery }\end{array}$ & $188(80.7)$ & $640(88.2)$ & \\
\hline CS & $45(19.3)$ & $86(11.8)$ & \\
\hline \multicolumn{3}{|c|}{ Postnatal depression $\neq$} & $<0.001 \dagger$ \\
\hline $\begin{array}{l}\text { Depressed }(n= \\
126)\end{array}$ & $74(58.7)$ & $52(41.3)$ & \\
\hline $\begin{array}{l}\text { Not depressed } \\
(n=466)\end{array}$ & $66(14.2)$ & $400(85.8)$ & \\
\hline \multicolumn{4}{|c|}{$C S=$ Caesarean section } \\
\hline \multicolumn{4}{|c|}{$\begin{array}{l}{ }^{*} \text { As the current study is a continuation of a previous study, some data } \\
\text { are the same. }{ }^{6} \text { The total of each variable corresponds to the number of } \\
\text { respondents for each question. 'Statistically significant at } P \leq 0.05 \text {. }{ }^{*} \text { A score } \\
\text { of } \geq 13 \text { on the Edinburgh Postnatal Depression Scale was indicative of } \\
\text { probable antenatal or postnatal depression. }\end{array}$} \\
\hline
\end{tabular}

defined as LBW. Women who delivered at $\geq 37$ weeks of gestation were categorised as having had a full-term delivery. ${ }^{17,18}$

A pilot study was conducted with the first 50 women to assess the clarity of the questions as well as the reliability of the Arabic version of the EPDS. The participants included in the pilot study were included in the final analysis of the current study. A Cronbach's alpha was calculated to test the reliability of the EPDS and it was found to be 0.766 .

Statistical analysis was conducted using Statistical Package for Social Sciences (SPSS), Version 23 (IBM Corp., Armonk, New York, USA). Descriptive analysis for sociodemographic variables and participants' responses were recorded. Relationships between antenatal depression, pregnancy outcomes and postnatal depression were assessed using a Chi-squared test. A $P$ value of $<0.05$ was considered statistically significant. Multivariate regression analysis was conducted to attenuate the effects of possible confounding factors. On multivariate regression analysis, the independent variables included gravidity (primigravida) and antenatal depression with CS delivery as the dependent variable. A second regression analysis was done for postnatal depression development (the dependent variable) and antenatal depression, with mother's age and unplanned pregnancy as the independent variables.
All participants provided informed consent and were given a form to read that explained the purpose of the study. This study was approved by the Medical Research and Ethics Committee (MREC) of the College of Medicine and Health Sciences at Sultan Qaboos University, Muscat, Oman (MREC \#572).

\section{Results}

A total of 959 pregnant women were included in this study (response rate: 97.3\%). The ages of participants ages ranged from $17-43$ years with a mean of $27 \pm 4.79$ years. The majority of participants were housewives (63.5\%) and the remaining participants (36.5\%) were employed. Regarding gravidity, $48.5 \%$ were multigravida (2-4 pregnancies), 38.9\% were primigravida and $12.6 \%$ were grand multigravida ( $5+$ pregnancies). Most women $(58.4 \%)$ were at $\geq 35$ weeks of gestation and the remaining participants (41.6\%) were between 32-34 weeks. More than $40 \%$ of participants reported that their pregnancy had been unplanned [Table 1].

The majority of participants (93.2\%) delivered at or after 37 weeks of gestation. Most (86.3\%) had normal vaginal deliveries and the remainder (13.7\%) had a CS. Of the CS deliveries, $82.4 \%$ were due to emergencies (i.e. non-progression of labour and/or fetal distress) and $17.6 \%$ were elective. In the majority of women (93.3\%), babies' birth weights were $2.5 \mathrm{~kg}$ or more [Table 1].

The EPDS scores ranged from 0-23, with a mean score of $9 \pm 4.785$. Of the 959 participants, 233 (24.4\%) had scores that suggested antenatal depression at a cut point of $\geq 13$.

More than half of participants (61.7\%) attended a postnatal follow-up at 6-8 weeks. Of these participants, $126(21.3 \%)$ had EPDS scores suggestive of postnatal depression using a cut point of $\geq 13$, of which, $58.7 \%$ had also had antenatal depression [Table 2]. A total of 367 (38.3\%) women were lost to follow-up as they did not attend postnatal follow-ups. Of these, 94 (25.6\%) had antenatal depression, which might have affected the results. However, such a percentage is not sufficiently high to substantially affect the outcome of this study.

A bivariate analysis revealed that depression during pregnancy was significantly associated with CS delivery $(P=0.004)$ and developing postnatal depression $(P<0.001)$. No significant associations were found between antenatal depression and LBW or preterm labour ( $P=0.177$ and 0.300 , respectively) [Table 2].

Gravidity (primigravida) and antenatal depression were found to be significantly associated with CS delivery $(P<0.001$ and 0.034 , respectively). Furthermore, 
Table 3: Associations between baseline variables and mode of delivery and postnatal depression among pregnant Omani women $(\mathrm{N}=959)$

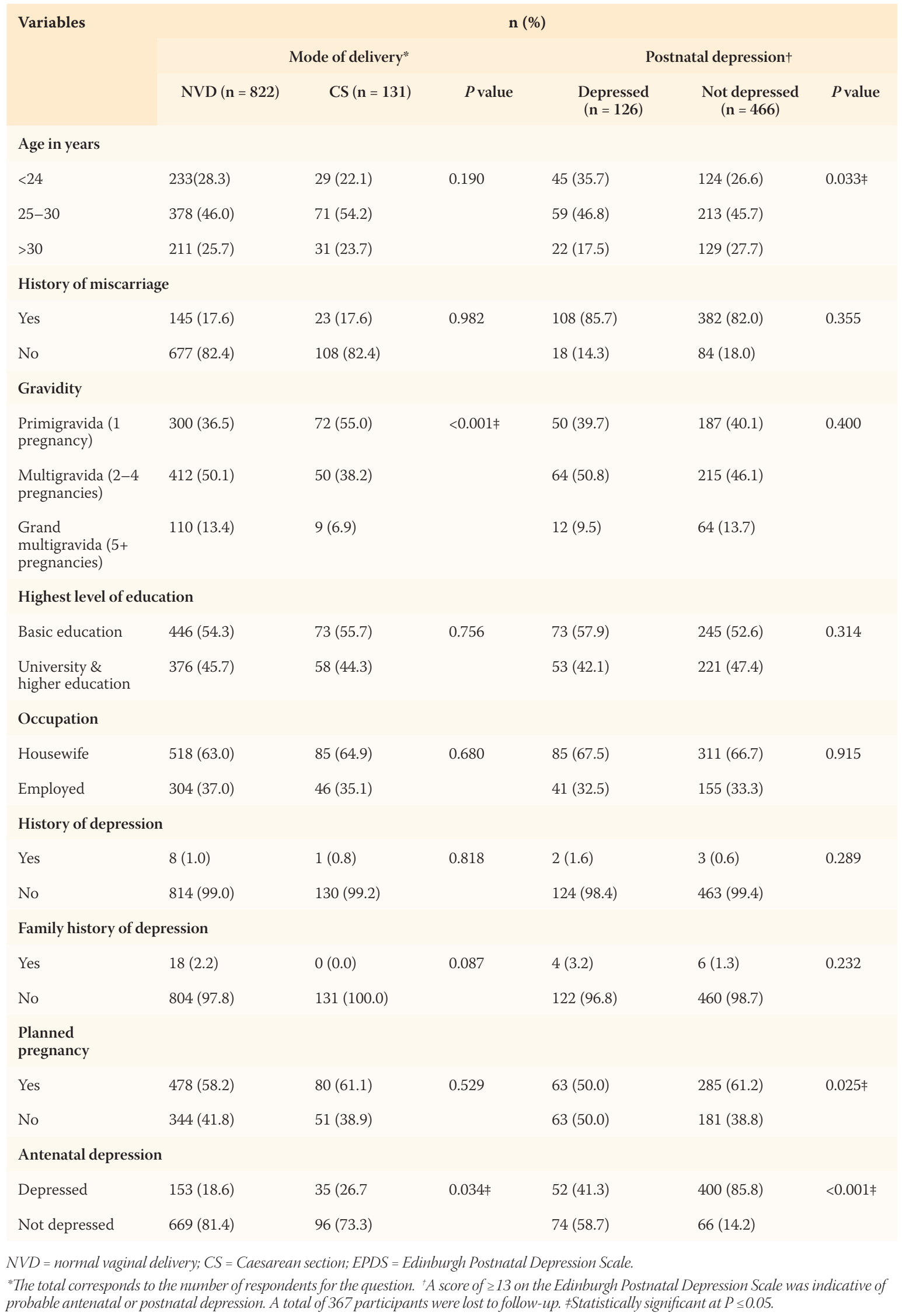
probable antenatal or postnatal depression. A total of 367 participants were lost to follow-up. $\neq$ Statistically significant at $P \leq 0.05$. 
Table 4: Logistic regression analysis of the effects of antenatal depression on birth outcomes and development of postnatal depression $(\mathrm{N}=959)$

$\begin{array}{llll}\text { Variables } & \text { OR } & \mathbf{9 5 \%} \text { CI } & \text { P value } \\ \text { CS* }^{*} & 1.79 & 1.20-2.66 & 0.004^{\dagger} \\ \begin{array}{l}\text { Postnatal } \\ \text { depression }\end{array} & 8.63 & 5.56-13.39 & <0.001^{\dagger}\end{array}$

$O R=$ odds ratio; $C I=$ confidence interval; $C S=$ Caesarean section . *Independent variables include gravidity and antenatal depression. ${ }^{\dagger}$ Statistically significant at $P \leq 0.05 .{ }^{7}$ Independent variables include mother's age, unplanned pregnancy and antenatal depression.

antenatal depression, mother's age and unplanned pregnancies were deemed significant predictors of postnatal depression development $(P<0.001,0.033$ and 0.025 , respectively) [Table 3].

The multivariate regression analysis revealed that women who had antenatal depression were 1.79 times more likely to undergo CS delivery (95\% CI: 1.20-2.66) and 8.63 times more likely to develop postpartum depression (95\% CI: 5.56-13.39) [Table 4].

\section{Discussion}

To the best of the author's knowledge, this study is the first in Oman to explore the association between antenatal depression and the outcomes of pregnancy, including postnatal depression development. It showed that antenatal depression is significantly associated with CS delivery and development of postnatal depression. However, effects of antenatal depression on gestational age at delivery and baby's birth weight were not significant.

This study found an antenatal depression prevalence among Omani women of $24.3 \%$ which was determined using a cut point of $\geq 13$ on the EPDS. ${ }^{6}$ This prevalence is similar to that of women in Brazil (24.3\%) but is higher than what has been reported in other Arabic-speaking countries such as Jordan (19\%) and Morocco (19.2\%), ${ }^{3,5,19}$ The prevalence of antenatal depression in Oman is higher than rates found in Bangladesh (18\%), Australia (16.9\%), Italy (14.9\%) and Turkey (21.6\%). ${ }^{20-23}$

The finding of a significant association between antenatal depression and CS delivery is consistent with other studies. ${ }^{24,25}$ The reason for the increased risk of CS in Omani women with antenatal depression is unclear. However, women who experience antenatal depression may have greater anxiety and fear of childbirth leading to a lower pain threshold and increased demand for epidural analgaesia and incidence of CS. ${ }^{8}$ Furthermore, it has been found that psychological distress can impair uterine contractility leading to prolonged labour, failure to progress and eventually fetal distress, all of which could increase CS risk..$^{26,27}$
The current study revealed that Omani women who had antenatal depression were at a greater risk of developing postnatal depression than women without antenatal depression. Similar results were reported in a study from the USA which showed that women who reported poor mental health at antenatal period were found to be 11 times as likely to develop poor mental health at postnatal period..$^{28}$ In another study, $23 \%$ of women with postnatal depression reported that symptoms of depression had started during pregnancy. ${ }^{29}$ It was also found that women who had experienced postnatal depression have an increased risk of suffering from further episodes of postnatal depression following subsequent deliveries. ${ }^{30}$

The current study found that antenatal depression had no effect on birth weight or gestational age at delivery (i.e. preterm birth), which was both consistent and inconsistent with previous studies. ${ }^{31-33}$ The reasons for these contradictory studies are most likely related to differences in study design, type of antenatal depression measurement tool used, the influence of confounders such as ethnicity, smoking and substance abuse and previous obstetric complications such as LBW or preterm labour. ${ }^{31}$ The absence of a positive association between antenatal depression and preterm birth might be related to the fact that in this study women were recruited from 32 weeks of gestation onward, resulting in an artificially low number of women in the study who had had preterm births.

This study was subjected to some limitations. First, the screening tool for depression was self-reported, resulting in a possible over- or underestimating of the true prevalence of depression. Moreover, choosing a cut-off value of $\geq 13$ to diagnose antenatal and postnatal depression was based on a Jordanian study as no previous validation study was conducted in Oman. ${ }^{3}$ Second, while EPDS is a valid and reliable screening tool for probable depression, it should be followed by more objective assessments to confirm the presence of depression. This study lacked such an objective assessment. Third, other confounding obstetric variables such as previous history of LBW and CS were not included in the current analysis and may have affected the findings. This study also did not identify the proportion of women with antenatal depression who developed obstetric and labour complications such as pre-eclampsia or obstructed labour, both of which might have had an impact on the mode of delivery. Fourth, this study did not determine whether women diagnosed with antenatal depression, based on the EPDS, had sought treatment from healthcare services. Moreover, types of treatment (e.g. cognitive behavioural therapy, medications or referral to a psychiatrist) those women might 
have received were not identified. Fifth, recruiting pregnant women at 32 weeks or more gestation might have resulted in the exclusion of women who delivered earlier, affecting the study's results. Finally, although telephone calls were used to remind women about the 6-8-week postnatal EPDS questionnaire, $38.3 \%$ of the women were lost to follow-up.

\section{Conclusion}

This study showed that antenatal depression has detrimental effects on both the mother and baby's health and is associated with several adverse outcomes in women, including the risk of postnatal depression. Screening women for the presence of antenatal depression and managing them appropriately may help reduce pregnancy and delivery complications. While no positive relationships were found between antenatal depression and a baby's gestational age or birth weight, additional research is needed to investigate this finding further.

\section{ACKNOWLEDGEMENT}

The authors would like to thank the participants in this study and the nurses from local health centres for their great help in data collection.

\section{CONFLICT OF INTEREST}

The authors declare no conflicts of interest.

\section{FUNDING}

This study was funded by the College of Medicine and Health Sciences, Sultan Qaboos University, Muscat, Oman.

\section{References}

1. World Health Organization, Department of Mental Health and Substance Abuse. Maternal mental health and child health and development in low and middle income countries. From: www.who.int/mental_health/prevention/suicide/mmh_jan08_ meeting_report.pdf Accessed: Nov 2019.

2. Underwood L, Waldie K, D'Souza S, Peterson ER, Morton S. A review of longitudinal studies on antenatal and postnatal depression. Arch Womens Ment Healt 2016; 19:711-20. https://doi.org/10.10 07/s00737-016-0629-1.

3. Mohammad KI, Gamble J, Creedy DK. Prevalence and factors associated with the development of antenatal and postnatal depression among Jordanian women. Midwifery 2011; 27:e238-45. https://doi.org/10.1016/j.midw.2010.10.008.

4. Milgrom J, Gemmill AW, Bilszta JL, Hayes B, Barnett B, Brooks J, et al. Antenatal risk factors for postnatal depression: A large prospective study. J Affect Disord 2008; 108:147-57. https://doi.org/10.1016/j.jad.2007.10.014.

5. Melo EF Jr, Cecatti JG, Pacagnella RC, Leite DF, Vulcani DE, Makuch MY. The prevalence of perinatal depression and its associated factors in two different settings in Brazil. J Affect Disord 2012; 136:1204-8. https://doi.org/10.1016/j.jad.2011.11.023.
6. Al-Azri M, Al-Lawati I, Al-Kamyani R, Al-Kiyumi M, Al-Rawahi A, Davidson R, et al. Prevalence and risk factors of antenatal depression among Omani women in a primary care setting: Crosssectional study. Sultan Qaboos Univ Med J 2016; 16:e35-41. https://doi.org/10.18295/squmj.2016.16.01.007.

7. Moses-Kolko EL, Roth EK. Antepartum and postpartum depression: Healthy mom, healthy baby. J Am Med Womens Assoc (1972) 2004; 59:181-91.

8. Chung TK, Lau TK, Yip AS, Chiu HF, Lee DT. Antepartum depressive symptomatology is associated with adverse obstetric and neonatal outcomes. Psychosom Med 2001; 63:830-4. https://doi.org/10.1097/00006842-200109000-00017.

9. Melville JL, Gavin A, Guo Y, Fan MY, Katon WJ. Depressive disorders during pregnancy: Prevalence and risk factors in a large urban sample. Obstet Gynecol 2010; 116:1064-70. https://doi.org/10.1097/AOG.0b013e3181f60b0a.

10. Larsson C, Sydsjö G, Josefsson A. Health, sociodemographic data, and pregnancy outcome in women with antepartum depressive symptoms. Obstet Gynecol 2004; 104:459-66. https://doi.org/10.1097/01.AOG.0000136087.46864.e4.

11. Fihrer I, McMahon CA, Taylor AJ. The impact of postnatal and concurrent maternal depression on child behaviour during the early school years. J Affect Disord 2009; 119:116-23. https://doi.org/10.1016/j.jad.2009.03.001.

12. O'Connor TG, Heron J, Glover V; Alspac Study Team. Antenatal anxiety predicts child behavioral/emotional problems independently of postnatal depression. J Am Acad Child Adolesc Psychiatry 2002; 41:1470-7. https://doi.org/10.1097/00004583200212000-00019.

13. Pearson RM, Evans J, Kounali D, Lewis G, Heron J, Ramchandani PG, et al. Maternal depression during pregnancy and the postnatal period: Risks and possible mechanisms for offspring depression at age 18 years. JAMA Psychiatry 2013; 70:1312-19. https://doi. org/10.1001/jamapsychiatry.2013.2163.

14. National Center for Statistics and Information. 2018 Statistical Year Book. From: ncsi.gov.om/Elibrary/LibraryContentDoc/ bar_Statistical\%20Year\%20Book\%202018_a8b32d59-cdc94987-ba29-1e7ce78d5cca.pdf Accessed: Nov 2019.

15. Oman Ministry of Health. Pregnancy \& Childbirth Management Guidelines. A Guide For Nurses, Midwives and Doctors. From: www.moh.gov.om/documents/272928/3240138/Pregnan $\mathrm{cy}+\% 26+$ Childbirth+Guideline+Level+2.pdf/01d4c976-83bb7a9d-12c4-9ed7d8a53041 Accessed: Nov 2019.

16. Heron J, O'Connor TG, Evans J, Golding J, Glover V; ALSPAC Study Team. The course of anxiety and depression through pregnancy and the postpartum in a community sample. J Affect Disord 2004; 80:65-73. https://doi.org/10.1016/j.jad.2003.08.004.

17. Niemi M, Falkenberg T, Petzold M, Chuc NT, Patel V. Symptoms of antenatal common mental disorders, preterm birth and low birthweight: A prospective cohort study in a semi-rural district of Vietnam. Trop Med Int Health 2013; 18:687-95. https://doi. org/10.1111/tmi.12101

18. Straub H, Adams M, Kim JJ, Silver RK. Antenatal depressive symptoms increase the likelihood of preterm birth. Am J Obstet Gynecol 2012; 207:329.e1-4. https://doi.org/10.1016/j. ajog.2012.06.033.

19. Alami KM, Kadri N, Berrada S. Prevalence and psychosocial correlates of depressed mood during pregnancy and after childbirth in a Moroccan sample. Arch Womens Ment Health 2006; 9:343-6. https://doi.org/10.1007/s00737-006-0154-8.

20. Nasreen HE, Kabir ZN, Forsell Y, Edhborg M. Low birth weight in offspring of women with depressive and anxiety symptoms during pregnancy: Results from a population based study in Bangladesh. BMC Pub Health 2010; 10:515. https://doi. org/10.1186/1471-2458-10-515.

21. Leigh B, Milgrom J. Risk factors for antenatal depression, postnatal depression and parenting stress. BMC Psychiatry 2008; 8:24. https://doi.org/10.1186/1471-244X-8-24. 
22. Agostini F, Neri E, Salvatori P, Dellabartola S, Bozicevic L, Monti F. Antenatal depressive symptoms associated with specific life events and sources of social support among Italian women. Matern Child Health J 2015; 19:1131-41. https://doi. org/10.1007/s10995-014-1613-x.

23. Gulseren L, Erol A, Gulseren S, Kuey L, Kilic B, Ergor G. From antepartum to postpartum: A prospective study on the prevalence of peripartum depression in a semiurban Turkish community. J Reprod Med 2006; 51:955-60.

24. Chung TK, Lau TK, Yip AS, Chiu HF, Lee DT. Antepartum depressive symptomatology is associated with adverse obstetric and neonatal outcomes. Psychosom Med 2001; 63:830-4. https://doi.org/10.1097/00006842-200109000-00017.

25. Bayrampour H, Salmon C, Vinturache A, Tough S. Effect of depressive and anxiety symptoms during pregnancy on risk of obstetric interventions. J Obstet Gynaecol Res 2015; 41:1040-8. https://doi.org/10.1111/jog.12683.

26. Kuo SY, Chen SR, Tzeng YL. Depression and anxiety trajectories among women who undergo an elective cesarean section. PLoS One 2014; 9:e86653. https://doi.org/10.1371/journal.pone.0086653.

27. Teixeira JM, Fisk NM, Glover V. Association between maternal anxiety in pregnancy and increased uterine artery resistance index: Cohort-based study. BMJ 1999;318:153-7. https://doi.org/10.11 36/bmj.318.7177.153.
28. Witt WP, Wisk LE, Cheng ER, Hampton JM, Creswell PD, Hagen EW, et al. Poor prepregnancy and antepartum mental health predicts postpartum mental health problems among US women: A nationally representative population-based study. Womens Health Issues 2011; 21:304-13. https://doi.org/10.10 16/j.whi.2011.01.002.

29. Watson JP, Elliott SA, Rugg AJ, Brough DI. Psychiatric disorder in pregnancy and the first postnatal year. Br J Psychiatry 1984; 144:453-62. https://doi.org/10.1192/bjp.144.5.453.

30. Robertson E, Grace S, Wallington T, Stewart DE. Antenatal risk factors for postpartum depression: A synthesis of recent literature. Gen Hosp Psychiatry 2004; 26:289-95. https://doi.org/10.10 16/j.genhosppsych.2004.02.006.

31. Grote NK, Bridge JA, Gavin AR, Melville JL, Iyengar S, Katon WJ. A meta-analysis of depression during pregnancy and the risk of preterm birth, low birth weight, and intrauterine growth restriction. Arch Gen Psychiatry 2010; 67:1012-24. https://doi. org/10.1001/archgenpsychiatry.2010.111.

32. AnderssonL, Sundström-PoromaaI, WulffM, AströmM,BixoM. Neonatal outcome following maternal antenatal depression and anxiety: A population-based study. Am J Epidemiol 2004; 159:872-81. https://doi.org/10.1093/aje/kwh122.

33. Rahman A, Bunn J, Lovel H, Creed F. Association between antenatal depression and low birthweight in a developing country. Acta Psychiatr Scand 2007; 115:481-6. https://doi. org/10.3389/fpsyt.2014.00175 